\title{
Rimonabant inhibits TNF- $\alpha$-induced endothelial IL-6 secretion via CB1 receptor and CAMP-dependent protein kinase pathway
}

\author{
Nan-lan HUANG ${ }^{1}$, Jyh-ming JUANG ${ }^{2}$, Yi-ho WANG ${ }^{1}$, Chia-hsiang HSUEH ${ }^{1}$, Yao-jen LIANG ${ }^{3}$, Jiunn-lee LIN $^{2}$, Chia-ti TSAl ${ }^{2, *}$, \\ Ling-ping $\mathrm{LAI}^{1,2, *}$ \\ ${ }^{1}$ Institute of Pharmacology, Collage of Medicine, National Taiwan University, Taipei, Taiwan, China; ${ }^{2}$ Department of Internal Medicine, \\ National Taiwan University Hospital,Taipei, Taiwan, China; ${ }^{3}$ Department and Institute of Life Science, Fu-Jen Catholic University, Taipei, \\ Taiwan, China
}

Aim: To investigate whether rimonabant, a cannabinoid receptor antagonist, had inhibitory effects on inflammatory reactions in human umbilical vein endothelial cells (HUVEC).

Methods: TNF- $\alpha$-induced IL- 6 production was measured by ELISA and effects on related signaling pathways were investigated by immunoblot analysis. Cellular cAMP level was measured using kinase-coupled luciferase reaction.

Results: Rimonabant at 1 and $10 \mu \mathrm{mol} / \mathrm{L}$ significantly inhibited TNF- $\alpha$-induced IL- 6 production when added 15, 30 and 60 minutes before TNF- $\alpha$ treatment. Rimonabant also inhibited TNF- $\alpha$-induced phosphorylation of IkB kinase (IKK) $\alpha / \beta$ and IKB- $\alpha$ degradation. ACEA, a cannabinoid receptor subtype 1 (CB1) agonist, added before rimonabant abolished the former effects of rimonabant. H-89, an inhibitor of CAMP-dependent protein kinase (PKA), abolished the inhibitory effects of rimonabant on TNF- $\alpha$ induced IL-6 production. Rimonabant also increased the phosphorylation of PKA regulatory subunit II (PKA-RII), implying the essential role of PKA activation in the inhibitory effects of rimonabant. Treatment with the phosphatidylinositol 3-kinase (PI3K) inhibitor, wortmannin did not abolish the inhibitory effects of rimonabant on TNF- $\alpha$ induced IL- 6 production.

Conclusion: Rimonabant had anti-inflammatory effects on endothelial cells and inhibited TNF- $\alpha$-induced IKK $\alpha / \beta$ phosphorylation, IKB- $\alpha$ degradation and IL-6 production in HUVEC. This effect was related to CB1 antagonism and PKA activation.

Keywords: rimonabant; CB1 receptor; CAMP-dependent protein kinase; endothelial cells; inflammation

Acta Pharmacologica Sinica (2010) 31: 1447-1453; doi: 10.1038/aps.2010.126; published online 18 Oct 2010

\section{Introduction}

The endocannabinoid system has recently emerged as a target for the pharmacological treatment of obesity and cardiometabolic risk factors ${ }^{[1]}$. The cannabinoid receptor subtype 1 (CB1) was the first identified and cloned cannabinoid receptor. Further studies revealed that this receptor is a G-protein coupled receptor ${ }^{[2]}$. Among the antagonists of the CB1 receptor, rimonabant [N-piperido-5-(4-chlorophenyl)1-(2,4-dichlorophenyl)-4-methylpyrazole-3-carboxamide; SR141716] is the first one to come into clinical use for treatment of multiple cardiovascular risk factors such as obesity, diabetes, hyperlipidemia and low high-density-lipoprotein

\footnotetext{
* To whom correspondence should be addressed.

E-mail fang31@ms39.hinet.net (Chia-ti TSAI); Iplai2003@ntu.edu.tw (Ling-ping LAI)

Received 2010-04-08 Accepted 2010-06-13
}

(HDL) cholesterol ${ }^{[3]}$. The central nervous system is enriched with the CB1 receptors. Blockade of CB1 receptor in the central nervous system, especially the hypothalamus, results in decreased food intake ${ }^{[3]}$. Furthermore, CB1 receptors are also present in peripheral tissues and blockade of peripheral CB1 might also contribute to its metabolic effects. For instance, CB1 blockade in adipose tissue induces decreased abdominal fat, increased adiponectin and HDL, decreased triglycerides (TG), low-density lipoprotein (LDL), C-reactive protein (CRP), decreased insulin resistance and glycosylated hemoglobin ${ }^{[1]}$. Rimonabant also stimulates 2-deoxyglucose uptake in skeletal muscle cells ${ }^{[4]}$.

It has been reported that there are also CB1 receptors in the cardiovascular system. Its role in the cardiovascular system and the effect of CB1 blockade are the focus of many recent researches. It has been shown that vascular and myocardial CB1 contribute to the modulation of blood pressure and heart 
rate $^{[5]}$. Protection against ischemia/reperfusion injury has also been reported for CB1 receptor blockade ${ }^{[5]}$.

Atherosclerosis is an important disease world-wide and it is the primary cause of many cardiovascular diseases including coronary artery disease, stroke, peripheral arterial occlusive disease and so on. There is growing evidence showing that atherosclerosis is an inflammatory disease ${ }^{[5,6]}$. Increased expression of pro-inflammatory cytokines such as tumor necrosis factor- $\alpha$ (TNF- $\alpha$ ) and interleukin-6 (IL-6) in arterial wall does not only reflect an inflammation status but also participates in the pathogenesis of atherosclerosis ${ }^{[6]}$. For instance, it has been shown that IL-6 enhanced fatty lesion development in mice ${ }^{[7]}$. Several drugs useful in treatment of cardiovascular diseases, such as HMG-CoA reductase inhibitors ${ }^{[8]}$ and metformin ${ }^{[9]}$, have been proved to possess anti-inflammatory effects.

In the present study, we investigate the possible anti-inflammatory effect of rimonabant in endothelial cells with a hope that this could be a potential novel treatment strategy for atherosclerosis. We used human umbilical vein endothelial cells (HUVEC) to investigate whether rimonabant suppressed the inflammatory responses in vascular endothelial cells. TNF- $\alpha$ was used to induce an inflammatory reaction in HUVEC. The effects of rimonabant and the potential roles of the CB1 receptor signal pathways were also studied.

\section{Materials and methods Materials}

Goat anti-rabbit IgG and anti-mouse IgG antibodies, $\beta$-actin, $\alpha$-tubulin, IKB-a monoclonal antibodies and IKKa/ $\beta$ polyclonal antibody were purchased from Santa Cruz Biotechnology (Santa Cruz, CA, USA). Rabbit phospho-PKA-RII $\left(\mathrm{Ser}^{96}\right)$ monoclonal antibody was purchased from Millipore Corporation and rabbit $\mathrm{CB} 1$ receptor polyclonal antibody from CHEMICON ${ }^{\circledR}$ International, Inc (Upstate, Temecula, CA, USA). Phospho-IKKa $\left(\operatorname{Ser}^{180}\right) / \mathrm{IKK} \beta\left(\operatorname{Ser}^{181}\right)$ polyclonal antibody were purchased from Cell Signaling Technology (Beverly, MA, USA).

\section{Cell isolation and culture experiments}

HUVEC were obtained from umbilical cords, digested with $0.05 \%$ of type II collagenase (Sigma Chemical Co, St Louis, MO, USA), and eluted with Medium199. Isolated HUVEC were cultivated in 20\% fetal bovine serum (FBS; Biological Industries, Kibbutz Beit Haemek, Israel) in M199 with endothelial cell growth supplement (ECGS, Upstate, Lake Placid, NY, USA) until confluent.

Passage 3-5 of HUVEC was incubated with 2\% FBS in M199 for 16-24 h before the experiments with 20\% FBS in M199. Rimonabant (Sanofi-Aventis, Montpellier, France) was added $15 \mathrm{~min}, 30 \mathrm{~min}$, or $1 \mathrm{~h}$ prior to treatment with human recombinant TNF-a (Peprotech Inc, Rocky Hill, NJ, USA). IкB- $a$ degradation and IKKa/ $\beta$ phosphorylation were measured 15 minutes after TNF-a incubation while IL-6 assay was performed 24 hours after TNF-a incubation. ACEA (arachidonyl2 '-chloroethylamide hydrate) was used as a CB1 receptor ago- nist. H-89 (N-[2-bromocinnamylamino)ethyl]-5-isoquinoline sulfonamide) was used as a PKA inhibitor, and wortmannin (Sigma Chemical Co, St Louis, MO, USA) was used as a PI3K inhibitor.

\section{Enzyme-linked immunosorbent assay of human IL-6}

Supernatants of the experiment media were collected and stored at $-80{ }^{\circ} \mathrm{C}$ until assayed with DuoSet巴 ELISA Development System (R\&D Systems, Minneapolis, USA) according to the manufacturer's instructions. In brief, plates were coated with the capturing antibody, which was diluted in phosphatebuffered saline (PBS, filtered through $0.22 \mu \mathrm{m}$ ), and washed with $0.05 \%$ Tween 20 in PBS before and after incubation with $1 \%$ bovine serum albumin (BSA) in PBS. Sequential dilutions of human IL-6 standard and experiment supernatants were incubated in coated plates for $2 \mathrm{~h}$, washed, and then reacted with the detection antibody (diluted with 1\% BSA in PBS) for $2 \mathrm{~h}$, and washed again. Streptavidin-HRP was added for 30 min before another wash and subsequent application with Tetramethylbezidine Substrate solution (Clinical Science Products Inc, MA, USA) until colorigenesis. $\mathrm{H}_{2} \mathrm{SO}_{4}(2.0 \mathrm{~mol} / \mathrm{L})$ was added to stop the reaction and the optical density of each well was determined immediately, using a microplate reader set to $450 \mathrm{~nm}$.

\section{Immunoblotting}

The protein samples from cell culture were denatured and subjected to sodium dodecyl sulfate-polyacrylamide gel electrophoresis (SDS-PAGE) and then transferred for immunoblot analysis using primary antibodies and subsequently with secondary antibodies. The proteins of interest were quantified using ImageQuant 5.0.

Measurement of cellular cAMP level

HUVEC were incubated with either DMSO or rimonabant for 10 min and subjected to cAMP-Glo ${ }^{\mathrm{TM}}$ Assay (Promega Corporation, USA) according to the manufacturer's instructions.

\section{Transfection of small interfering RNA into HUVEC}

Transfection of siRNA against cannabinoid receptor type 1 (CB1 siRNA, sense: 5'-UUCGUACUGAAUGUCAUUUGAGCCC-3', anti-sense: 5'-GGGCUCAAAUGACAUUCAGUACGAA-3'; Invitrogen ${ }^{\mathrm{TM}}$ ) into HUVEC was accomplished using Turbofect ${ }^{\mathrm{TM}}$ in vitro transfection reagent (Fermentas). After 12-16 h of transfection, the cells were incubated with $2 \%$ FBS in M199 for another 12-16 h and treated with rimonabant and TNF- $\alpha$ as indicated.

For mock control, siRNA against green fluorescent protein (control siRNA, sense: 5'-GGCUACGUCCAGGAGCGCACC-3', antisense: 5'-UGCGCUCCUGGACGUAGCCUU-3'; Dharmacon Inc, Lafayette, CO, USA) was used ${ }^{[10]}$.

\section{Statistical analysis}

Parametric data were normalized to the level of TNF-a alone, presented as mean \pm SEM and analyzed by $t$-test using SigmaPlot 9.0. A $P<0.05$ was considered statistically significant. 


\section{Results}

Rimonabant (SR141716) inhibits TNF- $\alpha$-induced IL-6 upregulation, IKK $\alpha / \beta$ phosphorylation and IKB- $\alpha$ degradation in endothelial cells

To examine the effect of rimonabant on TNF-a-induced IL-6 upregulation in HUVEC, we first performed concentration and time course experiments with rimonabant at $0.1,1$, or 10 $\mu \mathrm{mol} / \mathrm{L}$, added 15, 30 minutes or 1 hour prior to incubation with TNF-a (10 ng/mL). Rimonabant significantly inhibited TNF-a-induced upregulation of IL-6 at $1 \mu \mathrm{mol} / \mathrm{L}$ and 10 $\mu \mathrm{mol} / \mathrm{L}$ in all three time course experiments (Figure 1).

Because NF-kB pathway activation participates in TNF-ainduced IL-6 production in endothelial cells ${ }^{[9]}$, we investigated the effect of rimonabant on TNF-a-induced NF-kB pathway activation. Treatment with TNF-a $(10 \mathrm{ng} / \mathrm{mL})$ for $15 \mathrm{~min}$ resulted in a significant increase of phosphorylation of IKKa/ $\beta$ (Figure 2A) and degradation of IKB-a (Figure 2B). Both the increment of IKKa/ $\beta$ phosphorylation and the degradation of IкB- $\alpha$ induced by TNF- $\alpha$ were significantly reversed by 1 and $10 \mu \mathrm{mol} / \mathrm{L}$ of rimonabant. Treatment with rimonabant alone did not influence cellular level of IKB- $\alpha$ and IKK phosphorylation (Figure 2C).
The endothelial CB1 receptor is involved in the anti-inflammatory effects of rimonabant

Because rimonabant significantly reduced TNF-a induced changes, we examined whether the receptor of rimonabant was present in HUVEC. Immunoblotting of total cellular lysates from HUVEC and the neuroblastoma SH-SY5Y cells (serving as positive control) both demonstrated the existence of $\mathrm{CB} 1$ receptor (Figure 3A).

Since rimonabant is a competitive antagonist of human CB1 receptor, we tested whether the effects of rimonabant were blocked by ACEA, a CB1 agonist ${ }^{[11]}$. ACEA $(10 \mu \mathrm{mol} / \mathrm{L})$ was added either before or after treatment with rimonabant $(10 \mu \mathrm{mol} / \mathrm{L})$, which was followed by treatment with TNF-a. We demonstrated that ACEA blocked the inhibitory effects of rimonabant on TNF-a-induced IL-6 secretion (Figure 3B) only when it was added before rimonabant treatment. Pretreatment with ACEA also reversed the inhibitory effects of rimonabant on IKKa/ $\beta$ phosphorylation (Figure $3 \mathrm{C}$ ). These results suggested the involvement of CB1-binding in the effects of rimonabant. Treatment with ACEA alone did not significantly influence the secretion of IL-6 (Figure 3B).
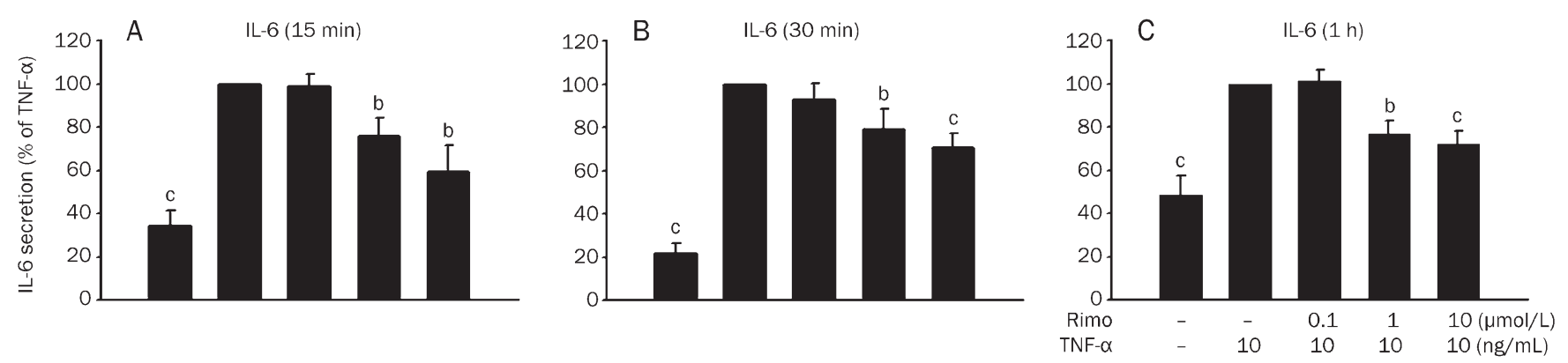

Figure 1. Rimonabant inhibited TNF- $\alpha$-induced IL-6 secretion in a concentration-dependent manner. HUVEC was incubated with vehicle (DMSO) or

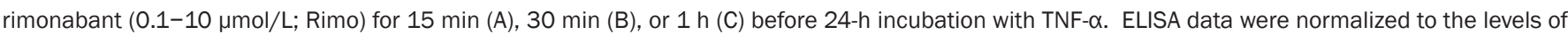
TNF- $\alpha$ at $10 \mathrm{ng} / \mathrm{mL}$ and expressed as mean \pm SEM ( $n=6-9) .{ }^{\mathrm{b}} P<0.05,{ }^{\mathrm{c}} P<0.01$ vs TNF- $\alpha$ alone.

A
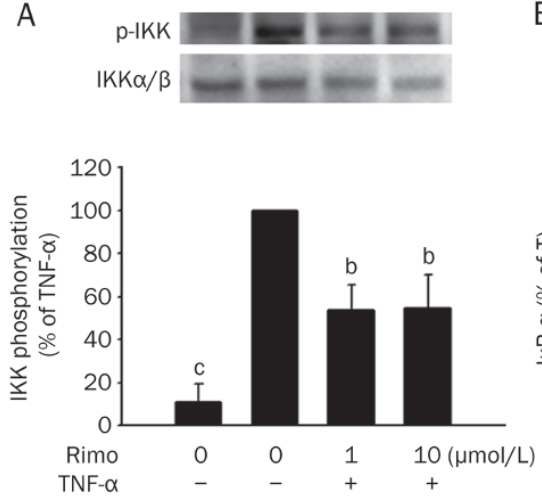
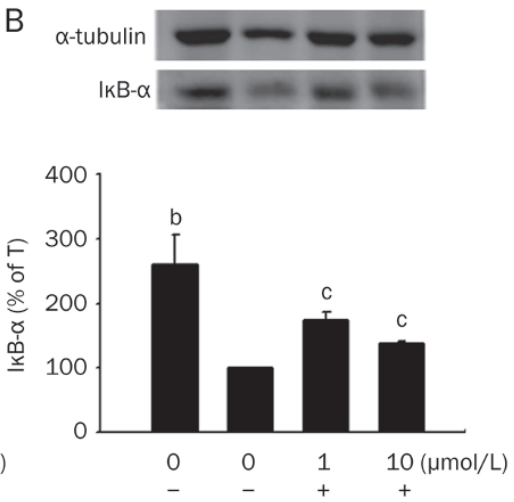

C
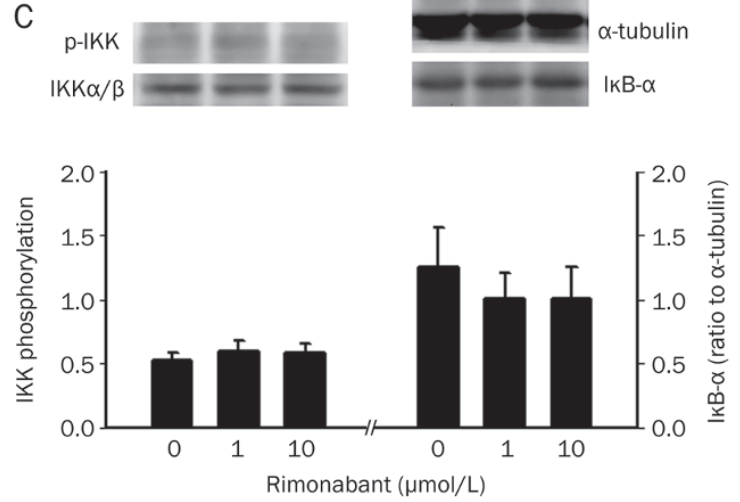

Figure 2. Effects of rimonabant on TNF- $\alpha$-induced NF-KB signal pathway. HUVEC was incubated with vehicle (DMSO) or rimonabant (1-10 $\mu$ mol/L) for $30 \mathrm{~min}$ before incubation with TNF- $\alpha$ for $15 \mathrm{~min}$. Cellular proteins were subjected to immunoblot analysis for measurement of phospho-IKK $\alpha / \beta$ (A) and IKB- $\alpha$ (B). Data were normalized to the level of TNF- $\alpha$ alone and presented as mean \pm SEM $(n=3-4) .{ }^{b} P<0.05$, ${ }^{C} P<0.01$ vs TNF- $\alpha$ alone. (C) Immunoblot of phospho-IKK $\alpha / \beta$ (normalized to IKK $\alpha / \beta, n=5$ ) and IKB- $\alpha$ (normalized to $\alpha$-tubulin, $n=4$ ) after treatment with either vehicle (DMSO) or rimonabant (1-10 $\mu \mathrm{mol} / \mathrm{L})$. There is no significant difference between vehicle and rimonabant group. 
A
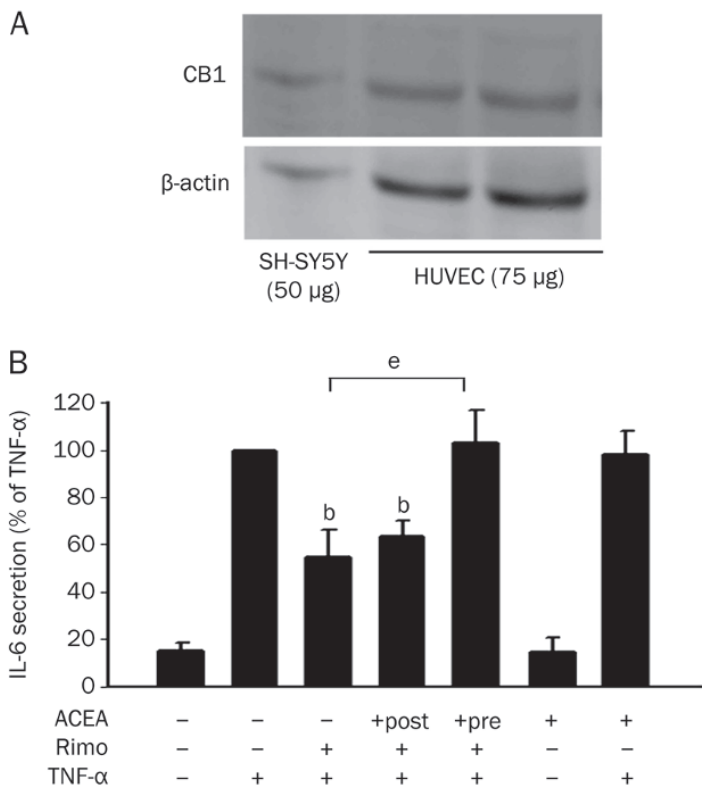

C
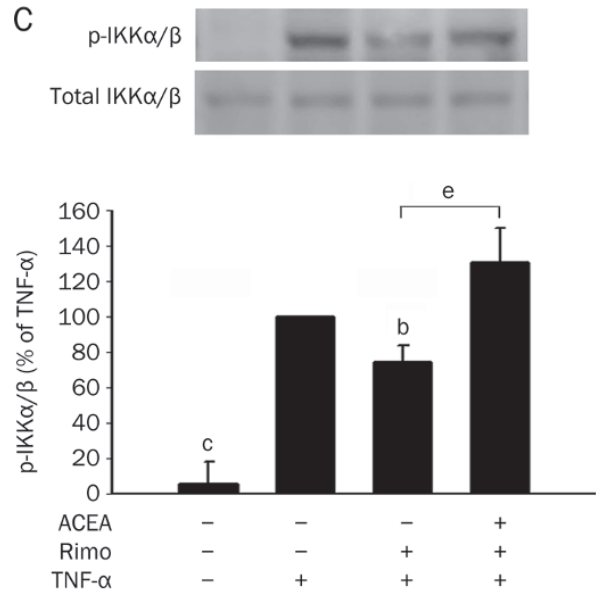

Figure 3. Involvement of $\mathrm{CB} 1$ receptor in the effects of rimonabant on TNF- $\alpha$-induced endothelial responses. (A) Expression of CB1 receptor was revealed by immunoblot analysis of cellular protein from SH-SY5Y $(50 \mu \mathrm{g})$ as well as HUVEC $(75 \mu \mathrm{g})$. The CB1 protein expression in HUVEC is quantitaively lower than that in $\mathrm{SH}-\mathrm{SY} 5 \mathrm{Y}$ cells, as demonstrated by differences between the volume of $\beta$-actin and CB1 protein. (B) Endothelial IL-6 secretion. Incubation with ACEA $(10 \mu \mathrm{mol} / \mathrm{L})$ was performed either before (ACEA+pre/Rimo+) or after (ACEA+post/Rimo+) the treatment with rimonabant $(10 \mu \mathrm{mol} / \mathrm{L})$, which was followed by treatment with TNF- $\alpha$. Data were normalized to the level of TNF- $\alpha$ alone and expressed as mean \pm SEM $(n=6-10)$. (C) IKK $\alpha / \beta$ phosphorylation. Cellular proteins were subjected to immunoblot analysis for measurement of phospho- and total-IKK $\alpha / \beta$. Data were normalized to the level of TNF- $\alpha$ alone and presented as mean $\pm \operatorname{SEM}(n=5-7)$. There is no significant difference between the parametric level of (TNF- $\alpha+$ ) and (ACEA+/Rimo+/ TNF- $\alpha+) .{ }^{\mathrm{b}} P<0.05,{ }^{\mathrm{c}} P<0.01$ vs TNF- $\alpha$ alone; ${ }^{\mathrm{e}} P<0.05$ vs Rimo+/TNF- $\alpha+$

The roles of protein kinases downstream of the CB1 receptor It has been reported that PKA is the downstream candidate of the CB1 receptor signal pathway ${ }^{[11]}$. Activation of CB1 receptor decreases the activity of PKA by the CB1-coupled Gi protein. Therefore, theoretically, inhibition of CB1 receptor by rimonabant should increase cellular cAMP and the activity of PKA.

To investigate the role of PKA in the inhibitory effects of rimonabant, H-89 (0.1-1 $\mu \mathrm{mol} / \mathrm{L})$ was applied to inhibit the PKA pathway. H-89 (0.3 and $1 \mu \mathrm{mol} / \mathrm{L})$ abolished the inhibitory effects of rimonabant on the TNF-a-induced secretion of IL-6 (Figure 4A), indicating the participation of PKA activation. Immunoblot analysis demonstrated that phosphorylation of PKA-RII subunit was increased by rimonabant in a concentration-dependent manner (Figure 5A). The increase in phospho-PKA-RII by rimonabant was prevented by pre-treatment with ACEA. Cellular cAMP level significantly increased after treatment with 1 and $10 \mu \mathrm{mol} / \mathrm{L}$ of rimonabant (Figure $5 B)$.
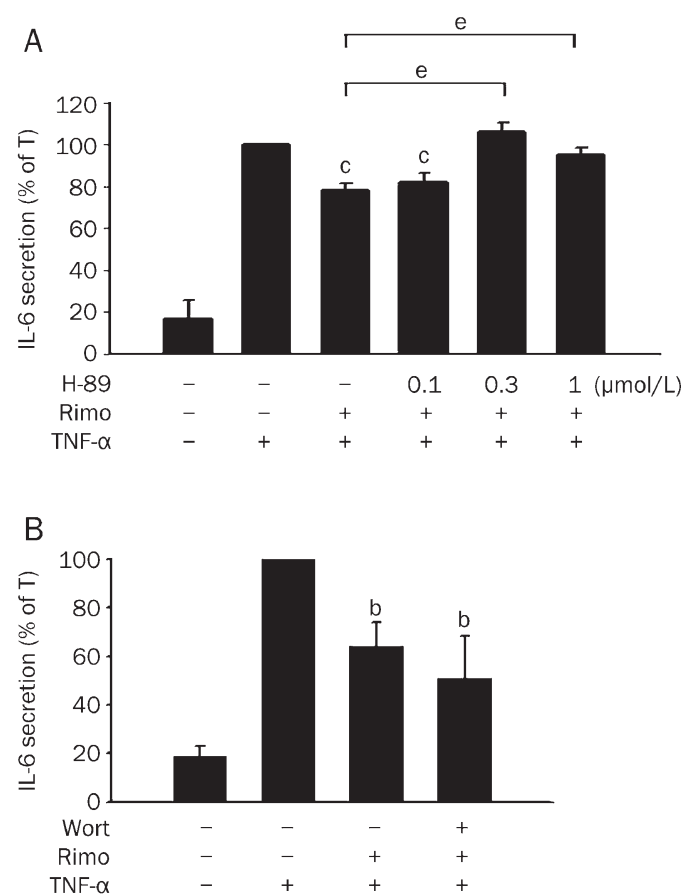

Figure 4. Roles of PKA and PI3K/Akt inhibitors on TNF- $\alpha$-induced endothelial IL-6 secretion. Incubation for 30 min with either $\mathrm{H}-89$ at 0.1-1 $\mu \mathrm{mol} / \mathrm{L}$ (A) or wortmannin at $0.1 \mu \mathrm{mol} / \mathrm{L}$ (B) was followed by 30-min rimonabant $(10 \mu \mathrm{mol} / \mathrm{L})$ and the subsequent $24-\mathrm{h}$ TNF- $\alpha$ treatment. Data were normalized to the level of TNF- $\alpha$ alone and expressed as mean \pm SEM ( $n=8-12$ for $\mathrm{H}-89$ and $n=6-7$ for wortmannin). ${ }^{\mathrm{b}} P<0.05,{ }^{\mathrm{c}} P<0.01 \mathrm{vs}$ TNF- $\alpha$ alone $;{ }^{e} P<0.05$ vs Rimo+/TNF- $\alpha+$.

On the other hand, rimonabant was reported to enhance phosphatidylinositol 3-kinase (PI3K)/ Akt activity in L6 cells. Whether rimonabant also influence PI3K/Akt pathway in endothelial cells was examined using the PI3K inhibitor wortmannin. Application of wortmannin $(100 \mathrm{nmol} / \mathrm{L})$, however, did not alter the inhibitory effects of rimonabant (Figure 4B). 
A
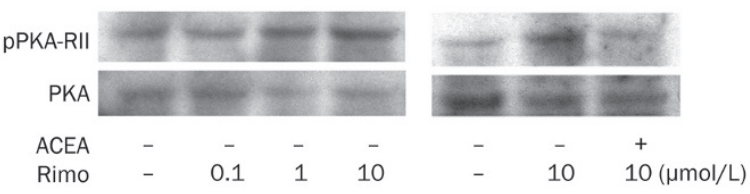

B

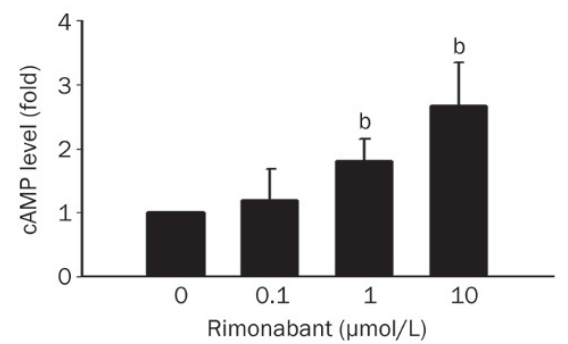

Figure 5. Effect of rimonabant on CAMP/PKA signal pathway. (A) Effect of rimonabant on PKA-RII phosphorylation. HUVEC was incubated with either vehicle (DMSO) or rimonabant $(0.1-10 \mu \mathrm{mol} / \mathrm{L})$ for $30 \mathrm{~min}$ and subjected to immunoblot analysis. For some experiments, ACEA $(10 \mu \mathrm{mol} / \mathrm{L})$ was added for 30 min before rimonabant as indicated. (B) Cellular cAMP levels after treatment with either vehicle (DMSO) or rimonabant (0.1-10 $\mu \mathrm{mol} / \mathrm{L})$ for $10 \mathrm{~min}$. Data were normalized to control $(0 \mu \mathrm{mol} / \mathrm{L})$ and expressed as mean \pm SEM $(n=4-5)$. ${ }^{\mathrm{b}} P<0.05$ vs control.

CB1 silencing abolished the inhibitory effects of rimonabant on TNF- $\alpha$-induced IL- 6 secretion.

To figure out the role of $\mathrm{CB} 1$ receptor in the effects of rimonabant on endothelial cells, transfection of siRNA into HUVEC was conducted. Immunoblot demonstrated the silencing of CB1 receptor in HUVEC (Figure 6A). In contrast to the concentration-dependent inhibition of TNF-a-induced IL-6 by rimonabant in control cells, rimonabant did not inhibit the induced IL-6 secretion by HUVEC with decreased CB1 expression (Figure 6B). Accordingly, endothelial CB1 receptor was necessary to the effects of rimonabant.

\section{Discussion}

In recent trials, CB1 receptor blockade with rimonabant has been reported to improve multiple cardiometabolic risk factors in overweight individuals with comorbidities ${ }^{[1]}$ and in abdominally obese patients with atherogenic dyslipidemia ${ }^{[12]}$. Whether rimonabant also inhibits vascular inflammation through CB1 receptor blockade is not full understood yet. It has been reported that rimonabant reduced plasma levels of the pro-inflammatory cytokines monocyte chemoattractant protein-1 (MCP-1) and interleukin-12 (IL-12) in LDLR-/- mice fed a Western-type diet ${ }^{[13]}$. Positive modulation of circulating neutrophil and monocyte numbers, reduced platelet activation and lower levels of MCP-1 and regulated upon activation, normal $\mathrm{T}$ cell expressed and secreted (RANTES) by rimonabant in type 2 diabetic Zucker rats have also been reported ${ }^{[14]}$. we demonstrated that TNF-a-induced IL-6 production, IKKa/ $\beta$ phosphorylation and IкB- $\alpha$ degradation were significantly attenuated by rimonabant in HUVEC.

To investigate whether the effects of rimonabant were medi-
A
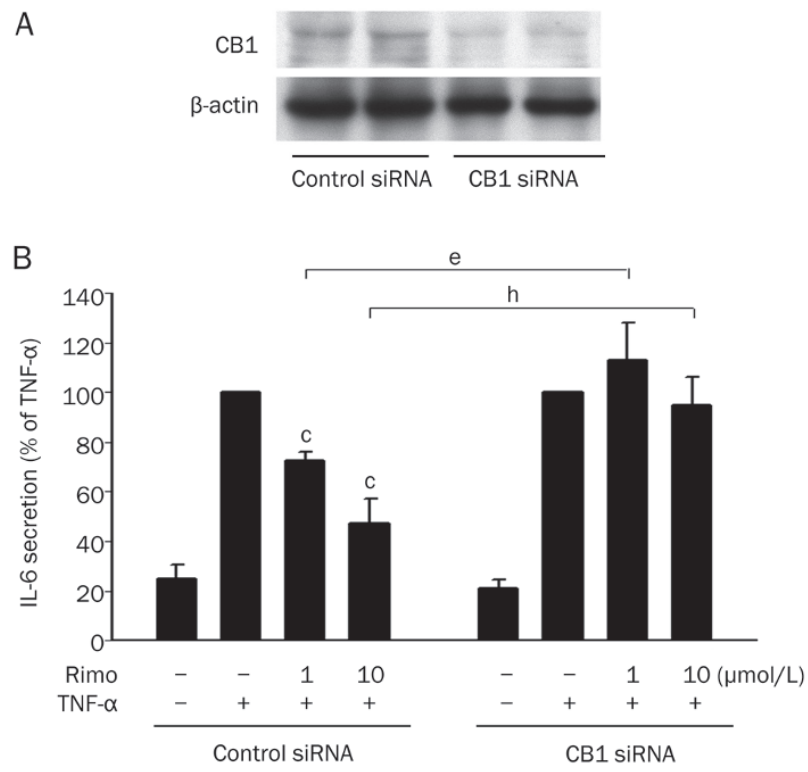

Figure 6. Silencing of $\mathrm{CB} 1$ receptor abolished the inhibitory effects of rimonabant on TNF- $\alpha$-induced endothelial IL-6 secretion. (A) Immunoblot of $\mathrm{CB} 1$ receptor revealed the efficiency of CB1 siRNA. (B) IL-6 secretion. HUVEC transfected with either control or CB1 siRNA was incubated with vehicle (DMSO) or rimonabant (1-10 $\mu \mathrm{mol} / \mathrm{L}$; Rimo) for $30 \mathrm{~min}$ before 24-h incubation with TNF- $\alpha$. ELISA data were normalized to the levels of TNF- $\alpha$ at $10 \mathrm{ng} / \mathrm{mL}$ and expressed as mean \pm SEM $(n=4-5) .{ }^{\mathrm{b}} P<0.05$, ${ }^{\mathrm{c}} P<0.01$ vs TNF- $\alpha$ alone; ${ }^{\mathrm{e}} P<0.05$ compared to Rimo $(1 \mu \mathrm{mol} / \mathrm{L}) / \mathrm{TNF}-\alpha+$ and ${ }^{\mathrm{h}} P<0.05$ vs Rimo $(10 \mu \mathrm{mol} / \mathrm{L}) / \mathrm{TNF}-\alpha+$ in control siRNA group.

ated through CB1 receptor, we first examined whether CB1 receptor was expressed in HUVEC. We chose the neuroblastoma SH-SY5Y cell line as a positive control in our experiments because the presence of CB1 receptor has been demonstrated by immunostaining and immunoblot analysis ${ }^{[15]}$. Protein lysate from SH-SY5Y and HUVEC were subjected to immunoblotting in juxtaposition. Blotting of protein from HUVEC revealed bands at the same molecular weight as that from SH-SY5Y cells, indicating the existence of CB1 receptor on HUVEC. Our results were in agreement with previous studies demonstrating the presence of CB1 receptor mRNA in endothelial cell culture ${ }^{[16]}$ and CB1 protein on endothelial cells in isolated rat hearts ${ }^{[17]}$. Vascular endothelial cells in tissue samples collected from neurosurgery of patients were also positive for CB1 receptor by immunohistochemical examination $^{[18]}$.

Recherche et al elucidated rimonabant as an antagonist ligand, with nanomolar affinity for CB1 but micromolar affinity for CB2 in ligand binding assay ${ }^{[2,19]}$. The dissociation constant of rimonabant for CB2 receptor was reported to be 13.2 $\mu \mathrm{mol} / \mathrm{L}^{[11]}$, a value that is higher than the effective concentration in the present study $(1 \mu \mathrm{mol} / \mathrm{L})$. Therefore, we assumed that the effects of rimonabant were likely mediated through CB1 receptor and ACEA was selected to examine whether CB1 receptor was involved in the effects of rimonabant. ACEA at $10 \mu \mathrm{mol} / \mathrm{L}$ was used in the experiments to selectively bind to CB1. This concentration was not high enough to block CB2 
because inhibition of forskolin-stimulated cAMP production by ACEA in $\mathrm{CHO}$ cells stably transfected with CB2 receptor required a concentration higher than $10 \mu \mathrm{mol} / \mathrm{L}^{[20]}$. We found that ACEA reversed the stimulated IL-6 secretion and phosphorylation of IKKa/ $\beta$ when it was added prior to rimonabant, while the inverse did not.

Since the expression of CB1 receptor in HUVEC was shown, and the effects of $\mathrm{CB} 1$ antagonist rimonabant was reversed by CB1 agonist ACEA, we transfected HUVEC with CB1 siRNA to confirm whether expression of CB1 receptor is essential in the effects of rimonabant. Silencing of CB1 receptor abolished the inhibitory effects of rimonabant on TNF- $\alpha$-induced IL-6 production. Taken together, the effects of rimonabant on HUVEC may be attributed to blockade of basal level of $\mathrm{G}_{\mathrm{i}}$-coupled CB1 receptor activity. Based on this assumption we would expect to see similar change to rimonabant treatment when CB1 receptor is silenced. However, cellular signal transduction is complex and there may be some limitation in experiments. Since reduction in CB1 receptor do not change TNF-a induced effects, all we can figure out is that rimonabant inhibits these effects through CB1-binding action.

CB1 receptor is coupled to $\mathrm{G}_{\mathrm{i}}$ and inhibits adenylate cyclase activity, reduces the production of cAMP and thereby attenuates the activity of $\mathrm{PKA}^{[2]}$. Rimonabant, as a CB1 antagonist, may relieve the negative regulation of cAMP level and consequently enhance the PKA activity. Incubation with H-89 (0.1-1 $\mu \mathrm{mol} / \mathrm{L})$ was conducted to test whether PKA played a role in the anti-inflammatory effects of rimonabant. As demonstrated by IL- 6 production, $\mathrm{H}-89$ at 0.3 and $1 \mu \mathrm{mol} / \mathrm{L}$ abolished the effect of rimonabant. These concentrations were similar to the $\mathrm{IC}_{50}$ of $\mathrm{H}-89$ for PKA $(0.135 \mu \mathrm{mol} / \mathrm{L})^{[21]}$. It was reported that adiponectin inhibits TNF- $\alpha$ induced endothelial hyperpermeability ${ }^{[22]}$ and endothelial IL-8 synthesis ${ }^{[23]}$. These inhibitory effects of adiponectin are abrogated by PKA inhibitors, consistent with the present study using TNF-a and rimonabant. Therefore, rimonabant and adiponectin may share similar signaling in terms of anti-inflammatory effect in endothelial cells.

We further performed immunoblot studies on type II regulatory subunit of PKA (PKA-RII) in HUVEC. Phosphorylation of PKA-RII subunit was suggested to regulate PKA-dependent substrate phosphorylation ${ }^{[24]}$. Phospho-PKA-RII was increased by rimonabant. Pre-treatment with the CB1 agonist ACEA reversed the rimonabant-induced increase in phospho-PKARII, implicating the involvement of phosphorylation activity of endothelial type II PKA in the effects of the CB1 antagonist rimonabant. To the best of our knowledge, the present study is the first to illustrate the expression of PKA-RII and alteration in phospho-PKA-RII by CB1 signal pathway in vascular endothelial cells. Measurement of cellular cAMP also demonstrated increased level after rimonabant treatment, indicating that there may be basal or constitutive CB1 receptor activity to suppress cellular CAMP generation.

Akt activation by CB1 receptor antagonist rimonabant has been reported in L6 skeletal muscle cells and in mouse primary myocytes ${ }^{[4]}$. In these cells, rimonabant increased 2-deoxyglucose uptake, which was blunted by co-incubation with the
PI3K inhibitor LY294002. In our experiments, we found that treatment with the PI3K inhibitor wortmannin had no effects on the inhibition of IL-6 induction by rimonabant, suggesting that PI3K/Akt pathway was not involved in the effects of rimonabant on HUVEC. The discrepancy might be related to different cell types.

In summary, we demonstrated the inhibitory effects of rimonabant on TNF-a-induced NF-KB pathway activation and IL-6 production. These effects of rimonabant might be attributed to blockade of CB1 receptor and the subsequent activation of cAMP/PKA pathway. These effects might serve as a new therapeutic strategy for atherosclerosis.

\section{Acknowledgements}

This study was supported in part by a grant from the National Taiwan University Hospital NTUH(97S805).

\section{Author contribution}

Nan-lan HUANG and Chia-ti TSAI designed the research; Nan-lan HUANG and Yi-ho WANG performed the experiments; Jyh-ming JUANG, Jiunn-lee LIN, Yao-jen LIANG, and Chia-hsiang HSUEH contributed to reagents or analytic tools; Nan-lan HUANG analyzed the data and wrote the article; Chia-ti TSAI and Ling-ping LAI revised the article.

\section{References}

1 Aronne LJ, Isoldi KK. Cannabinoid-1 receptor blockade in cardiometabolic risk reduction: Efficacy. Am J Cardiol 2007; 100: S18-S26.

2 Howlett AC. Pharmacology of Cannabinoid Receptors. Annu Rev Pharmacol 1995; 35: 607-34.

3 Gelfand EV, Cannon CP. Rimonabant: a cannabinoid receptor type 1 blocker for management of multiple cardiometabolic risk factors. J Am Coll Cardiol 2006; 47: 1919-26.

4 Esposito I, Proto MC, Gazzerro P, Laezza C, Miele C, Alberobello AT, et al. The cannabinoid $\mathrm{CB} 1$ receptor antagonist rimonabant stimulates 2-deoxyglucose uptake in skeletal muscle cells by regulating the expression of phosphatidylinositol-3-kinase. Mol Pharmacol 2008; 74: 1678-86.

5 Mach F, Montecucco F, Steffens S. Cannabinoid receptors in acute and chronic complications of atherosclerosis. Br J Pharmacol 2008; 153: $290-98$.

6 Hansson GK. Inflammation, atherosclerosis, and coronary artery disease. N Engl J Med 2005; 352: 1685-95.

7 Tedgui A, Mallat Z. Cytokines in Atherosclerosis: Pathogenic and Regulatory Pathways. Physiol Rev 2006; 86: 515-81.

8 Patel TN, Shishehbor MH, Bhatt DL. A review of high-dose statin therapy: targeting cholesterol and inflammation in atherosclerosis. Eur Heart J 2007; 28: 664-72.

9 Huang NL, Chiang SH, Hsueh CH, Liang YJ, Chen YJ, Lai LP. Metformin inhibits TNF- $\alpha$-induced IKB kinase phosphorylation, IKB- $\alpha$ degradation and IL-6 production in endothelial cells through PI3K-dependent AMPK phosphorylation. Int J Cardiol 2009; 134: 169-75.

10 Liang YJ, Shyu KG, Wang BW, Lai LP. C-reactive protein activates the nuclear factor-KB pathway and induces vascular cell adhesion molecule-1 expression through CD32 in human umbilical vein endothelial cells and aortic endothelial cells. J Mol Cell Cardiol 2006; 40: 412-20.

11 Howlett AC, Barth F, Bonner TI, Cabral G, Casellas P, Devane WA, et al. International Union of Pharmacology. XXVII. Classification of 
Cannabinoid Receptors. Pharmacol Rev 2002; 54: 161-202.

12 Després JP, Ross R, Boka G, Alméras N, Lemieux I, ADAGIO-Lipids Investigators . Effect of rimonabant on the high-triglyceride/ low-HDLcholesterol dyslipidemia, intraabdominal adiposity, and liver fat: the ADAGIO-lipids trial. Arterioscler Thromb Vasc Biol 2009; 29: 416-23.

13 Dol-Gleizes F, Paumelle R, Visentin V, Marés A-M, Desitter P, Hennuyer $\mathrm{N}$, et al. Rimonabant, a selective cannabinoid CB1 receptor antagonist, inhibits atherosclerosis in LDL receptor-deficient mice. Arterioscler Thromb Vasc Biol 2009; 29: 12-18.

14 Schafer A, Pfrang J, Neumuller J, Fiedler S, Ertl G, Bauersachs J. The cannabinoid receptor-1 antagonist rimonabant inhibits platelet activation and reduces pro-inflammatory chemokines and leukocytes in Zucker rats. Br J Pharmacol 2008; 154: 1047-54.

15 Marini P, Moriello AS, Cristino L, Palmery M, De Petrocellis L, Di Marzo V. Cannabinoid CB1 receptor elevation of intracellular calcium in neuroblastoma SH-SY5Y cells: Interactions with muscarinic and [delta]opioid receptors. Biochim Biophys Acta 2009; 1793: 1289-303.

16 Sugiura T, Kodaka T, Nakane S, Kishimoto S, Kondo S, Waku K. Detection of an endogenous cannabimimetic molecule, 2-arachidonoylglycerol, and cannabinoid CB1 receptor mRNA in human vascular cells: is 2-arachidonoylglycerol a possible vasomodulator? Biochem Biophys Res Commun 1998; 243: 838-43.

17 Lepicier P, Lagneux C, Sirois MG, Lamontagne D. Endothelial CB1receptors limit infarct size through $\mathrm{NO}$ formation in rat isolated hearts. Life Sci 2007; 81: 1373-80.
18 Schley M, Ständer S, Kernerd J, Vajkoczy P, Schüpfer G, Dusch M, et al. Predominant $\mathrm{CB} 2$ receptor expression in endothelial cells of glioblastoma in humans. Brain Res Bull 2009; 79: 333-37.

19 Rinaldi-Carmona M, Barth F, Heaulme M, Shire D, Calandra B. SR141716A, a potent and selective antagonist of the brain cannabinoid receptor. FEBS Lett 1994; 350: 240.

20 Hillard CJ, Manna S, Greenberg MJ, Dicamelli R, Ross RA, Stevenson $\mathrm{LA}$, et al. Synthesis and characterization of potent and selective agonists of the neuronal cannabinoid receptor (CB1). J Pharmacol Exp Ther 1999; 289: 1427-33.

21 Lochner A, Moolman JA. The many faces of H89: a review. Cardiovasc Drug Rev 2006; 24: 261-74.

22 Xu SQ, Mahadev K, Wu X, Fuchsel L, Donnelly S, Scalia RG, et al. Adiponectin Protects Against Angiotensin II or Tumor Necrosis Factor $\alpha$-Induced Endothelial Cell Monolayer Hyperpermeability: Role of cAMP/PKA Signaling. Arterioscler Thromb Vasc Biol 2008; 28: 899905.

23 Kobashi C, Urakaze M, Kishida M, Kibayashi E, Kobayashi H, Kihara S, et al. Adiponectin Inhibits Endothelial Synthesis of Interleukin-8. Circ Res 2005; 97: 1245-52.

24 Manni S, Mauban JH, Ward CW, Bond M. Phosphorylation of the PKA regulatory subunit modulates PKA-AKAP interaction, substrate phosphorylation and calcium signaling in cardiac cells. J Biol Chem 2008; 283: $24145-54$. 